SOI: $1.1 /$ TAS $\quad$ DOI: $10.15863 / \mathrm{TAS}$ International Scientific Journal Theoretical \& Applied Science

p-ISSN: 2308-4944 (print) e-ISSN: 2409-0085 (online)

Year: $2016 \quad$ Issue: 5 Volume: 37

Published: $30.05 .2016 \quad \underline{\text { http://T-Science.org }}$
Sergey Alexandrovich Mishchik Associate Professor, Candidate of Pedagogical Science, Corresponding member of International Academy TAS, Assistant professor Department of Physics, State Maritime University Admiral Ushakov, Russia, sergei_mishik@mail.ru

SECTION 21. Pedagogy. Psychology. Innovation in Education

\title{
ADAPTIVE PREDICTION PEDAGOGOMETRICHESKOY STRUCTURE STAGES OF FORMATION OF INTEGRITY-SYSTEM CYCLE LIFE OF EDUCATIONAL FACILITIES
}

Abstract: Offered adaptive prediction pedagogometricheskoy structure stages of formation of integrity-system cycle life of educational facilitiesholistic system of life-through the use of twelve pointed star as the lead Ertsgammy formative processes regarding the psycho-pedagogical activity theory, psycho-pedagogical system analysis and the theory of the formation of mental actions. We consider the holistic development of integrity-system cycle regarding the existence and characteristics of the external and internal structure of the educational space.

Key words: adaptive prediction, stage, pedagogometrika, consistency, integrity, stakeholders, personality analysis, star Ertsgammy, educational space.

Language: Russian

Citation: Mishchik SA (2016) ADAPTIVE PREDICTION PEDAGOGOMETRICHESKOY STRUCTURE STAGES OF FORMATION OF INTEGRITY-SYSTEM CYCLE LIFE OF EDUCATIONAL FACILITIES. ISJ Theoretical \& Applied Science, 05 (37): 78-84.

Soi: http://s-o-i.org/1.1/TAS-05-37-15 Doi: crossef http://dx.doi.org/10.15863/TAS.2016.05.37.15

\section{УДК 372.851}

\section{АДАПТИВНОЕ ПРОГНОЗИРОВАНИЕ ПЕДАГОГОМЕТРИЧЕСКОЙ СТРУКТУРЫ ЭТАПОВ ФОРМИРОВАНИЯ ЦЕЛОСТНО-СИСТЕМНЫХ ЦИКЛОВ ЖИЗНЕДЕЯТЕЛЬНОСТИ ОБРАЗОВАТЕЛЬНЫХ ОБЪЕКТОВ}

\begin{abstract}
Аннотация: предложено адаптивное прогнозирование педагогометрической структуры этапов формирования целостно-системных циклов жизнедеятельности образовательных объектов через применение двенадцати конечной звезды Эригаммы в качестве ведущего формообразовательного прочесса относительно психолого-педагогической теории деятельности, психолого-педагогического системного анализа и теории формирования умственных действий. Рассматривается иелостное развитие ичелостносистемного циикла относительно особенностей внешней и внутренней структуры образовательного пространства.
\end{abstract}

Ключевые слова: адаптивное прогнозирование, этап, педагогометрика, системность, иелостность, субъект деятельность, личность, анализ, звезда Эризаммы, образовательное пространство.

\section{Адаптивное} педагогометрической формирования целостно-системных циклов жизнедеятельности образовательных объектов есть многоэтапный процесс. Преобразование внешнего образа мира во внутренний происходит в результате постепенной различно функциональной деятельности, которая отражает базисные рефлекторно-физиологические этапы процесса интериоризации относительно общего процесса познания. Педагогометрический анализ данных процессов позволит проводить плановое моделирование условиями подготовки широкопрофильных специалистов и управление формированием профессиональных качеств личности.

Седьмой этап формирования целостносистемного цикла жизнедеятельности связан с целостно-системной обонятельностью, которая выражает одну из следующих орудийных средств познания окружающего мира. Целостносистемная обонятельность - есть одна из высших 
форм взаимодействия с окружающим миром на основе целостно-системной ориентировочномотивационной деятельности обонятельного восприятия действительности. Целостносистемная обонятельность выражает особую целостно-системную обонятельную жизнедеятельность, которая возникает и формируется на основе инвариантной структуры жизнедеятельности и определяет соответствующий уровень целостно-системной обонятельной ориентировки, исполнения и контроля обонятельного восприятия [1].

Целостно-системная обонятельная жизнедеятельность задаётся общим развитием целостно-системного субъекта и, в первую очередь, определяется соответствующими параметрами начального состояния целостносистемного обонятельного субъекта, который характеризуется обонятельными целостными свойствами через пространственные, временные, гравитационные, силовые, энергетические, ориентировочные, исполнительные и контрольные параметры.

Целостно-системный обонятельный субъект (ЦСОС) овладевает обобщённой целостносистемной обонятельной деятельностью (ЦСОД), которая формируется по базисным характеристикам деятельности, действия и операции в процессе их развития. Это позволяет приступить к освоению целостно-системных обонятельных средств деятельности (ЦСОСД), которые характеризуются определёнными параметрами, а также относительными сочетаниями их характеристик, которые отражают особенную целостно-системную технологию обонятельного восприятия мира относительной общей цели развития целостносистемного субъекта.

Возникающая технология целостносистемных обонятельных средств деятельности направлена на соответствующие целостносистемные обонятельные предметы деятельности (ЦСОПД), которые отражают определённые внешние параметры относительно силовых, гравитационных, энергетических, временных, пространственных, ориентационных, исполнительных и контрольных характеристик, их сочетаний и перестановок обонятельного предметного образа. При этом образуется целостно-системная обонятельная контрольная деятельность (ЦСОКД), которая в результате базисного структурного цикла ориентировки, исполнения и контроля устанавливает изоморфное соответствие между обонятельными образами и прообразами обонятельной предметности [2].

Результатом

целостно-системной обонятельной контрольной деятельности является целостно-системный обонятельный продукт деятельности (ЦСОПРД). который является многофункциональным субъектносредственным предметом саморазвития целостно-системного обонятельного субъекта. Первой деятельной формой активации ЦСОПРД является целостно-системная обонятельная ритуальная деятельность (ЦСОРД), которая отражает особенные формы проявления активности ориентировочно-го, исполнительного и контрольного характера по установлению целостно-системной опредмеченной обонятельной потребности (ЦСООП).

Целостно-системная опредмеченная обонятельная потребность является псевдосредством новой формы саморазвития целостно-системного обонятельного субъекта. ЦСООП вызывает кардинальную форму целостно-системной обонятельной восходящей деятельности (ЦСОВД), которая формирует целостно-системный обонятельный компаундсубъект (ЦСОКС). Он определяется как псевдо предмет самоформирования целостно-системного обонятельного супер-субъекта деятельности (ЦСОССД). Процесс перехода к высшей форме обонятельных субъектных отношений происходит через целостно-системную обонятельную развивающую деятельность (ЦСОРД), которая формирует ЦСОССД в результате выполнения базисных ориентировочных, исполнительных и контрольных обонятельных форм деятельности. Возникающий целостно-системный обонятельный супер-субъект деятельности отражает весь смыслообразующий компонент всего процесса целостно-системной обонятельной жизнедеятельности (ЦСОЖД).

Каждый элемент целостно-системной обонятельной жизнедеятельности имеет системное представление. На первом этапе системного анализа устанавливаются общие контуры системного представления с определением характеристик порождающей среды, внешних свойств элементов, уровней анализа, их структуры, формы организации, поведения и начальные прогнозы развития. В дальнейшем происходит раскрытие детализаций процесса целостно-системной обонятелизации, как особой формы жизнедеятельности и этапа формирования абсолютной целостно-системной обонятельной супер-личности, которая способна на данном этапе интери-оризационного развития устанавливать пространственные, силовые, энергетические, временные, гравитационные, ориентировочные, исполнительные и контрольные параметры обонятельного восприятия, относительно структурных и системообразующих связей обонятелизации образа внешнего мира, а также определять сложность, упорядоченность и разнообразие 
обонятельного ряда развития в условиях статического и динамического обонятельного ощущения относительно перспектив саморазвития субъекта.

Восьмой этап формирования целостносистемного цикла жизнедеятельности связан с целостно-системной материальностью, которая выражает одну из следующих орудийных средств познания окружающего мира. Целостносистемная материальность - есть одна из высших форм взаимодействия с окружающим миром на основе целостно-системной ориентировочномотивационной деятельности материального восприятия действительности. Целостносистемная материальность выражает особую целостно-системную материальную жизнедеятельность, которая возникает и формируется на основе инвариантной структуры жизнедеятельности и определяет соответствующий уровень целостно-системной ориентировки, исполнения и контроля материального восприятия [3].

Целостно-системная

материальная жизнедеятельность задаётся общим развитием целостно-системного субъекта и, в первую очередь, определяется соответствующими параметрами начального состояния целостносистемного материального субъекта, который характеризуется материальными и гравитационными, силовыми, энергетическими, ориентировоч-ными исполнительными и контрольными параметрами.

Целостно-системный материальный субъект (ЦСМС) овладевает обобщённой целостносистемной материальный деятельностью (ЦСМД), которая формируется по базисным характеристикам деятельности, действия и операции в процессе их развития. Это позволяет приступить к освоению целостно-системных материальных средств деятельности (ЦСМСД), которые характеризуются определёнными параметрами, а также относительными сочетаниями их характеристик, которые отражают особенную целостно-системную технологию материального восприятия мира относительной общей цели развития целостносистемного субъекта.

Возникающая технология целостносистемных материальных средств деятельности направлена на соответствующие целостносистемные материальные предметы деятельности (ЦСМПД), которые отражают определённые внешние параметры относительно силовых, гравитационных, энергетических, временных, пространственных, ориентационных, исполнитель-ных и контрольных характеристик, их сочетаний и перестановок материального предметного образа. При этом образуется целостно-системная материальная контрольная деятельность (ЦСМКД), которая в результате базисного структурного цикла ориентировки, исполнения и контроля устанавливает изоморфное соответствие между материальными образами и прообразами материальной предметности.

Результатом

целостно-системной материальной контрольной деятельности является целостно-системный материальный продукт деятельности (ЦСМПРД). который является многофункциональным субъектносредственным предметом саморазвития целостно-системного материального субъекта. Первой деятельной формой активации ЦСМПРД является це-лостно-системная материальная ритуальная деятельность (ЦСМРД), которая отражает особенные формы проявления активности ориентировочного, исполнительного и контрольного характера по установлению целостно-системной опредмеченной материальной потребности (ЦСОМП) [4].

Целостно-системная опредмеченная материальная потребность является псевдосредством новой формы саморазвития целостно-системного материальноного субъекта. ЦСОМП вызывает кардинальную форму целостно-системной материальной восходящей деятельности (ЦСМВД), которая формирует целостно-системный материальной компаундсубъект (ЦСМКС). Он определяется как псевдо предмет самоформирования целостно-системного материального супер-субъекта деятельности (ЦСМССД). Процесс перехода к высшей форме материальных субъектных отношений происходит через целостно-системную материальную развивающую деятельность (ЦСМРД), которая формирует ЦСМССД в результате выполнения базисных ориентировочных, исполнительных и контрольных материальных форм деятельности. Возникающий целостно-системный материальный супер-субъект деятельности отражает весь смыс-лообразующий компонент всего процесса целостно-системной материальной жизнедеятельности (ЦСМЖД).

Каждый элемент целостно-системной материальной жизнедеятельности имеет системное представление. На первом этапе системного анализа устанавливаются общие контуры системного представления с определением характеристик порождающей среды, внешних свойств элементов, уровней анализа, их структуры, формы организации, поведения и начальные прогнозы развития. В дальнейшем происходит раскрытие детализаций процесса целостно-системной материализации, как особой формы жизнедеятельности и этапа формирования абсолютной целостно-системной материальной супер-личности, которая способна 
на данном этапе интериоризационного развития устанавливать пространственные, силовые, энергетические, временные, гравитационные, ориентировочные, исполнительные и контрольные параметры материального восприятия, относительно структурных и системообразующих связей материализации образа внешнего мира, а также определять сложность, упорядоченность и разнообразие материального ряда развития в условиях статического и динамического материального ощущения относительно перспектив саморазвития субъекта [5].

Девятый этап формирования целостносистемного цикла жизнедеятельности определяется целостно-системной рецепторностью (ЦСР), которая устанавливает дальнейшее освоение орудийных средств познания рецепторного образа мира. Целостносистемная рецепторность - выражает высшую форму взаимодействия с окружающим миром на основе целостно-системной мультирефлексивной деятельности рецепторного восприятия действительности. Целостно-системная рецепторность выражает определённую целостно-системную рецепторную жизнедеятельность, которая возникает и формируется на основе инвариантно-обобщённой структуры жизнедеятельности и устанавливает соответствующий уровень целостно-системной рецепторной ориентировки, исполнения и контроля восприятия рецепторной системы мира.

Целостно-системная рецепторная жизнедеятельность (ЦСРЖ) начинается с выражения собственного рецепторного «Я» начального целостно-системного рецепторного субъекта (НЦСРС), который обладает набором целостных рецепторных характеристик относительно их внешних рецепторных инвариантных образов, устанавливающих рецепторный ряд параметров.

К таким внешним рецепторным характеристикам относятся пространственные, временные, гравитационные, силовые, энергетические, ориентационные, исполнительные и контрольные величины, определяющие начальные рецепторные образы. Процесс реализации начальных рецепторных возможностей начинает реализовываться через освоение всеобщей целостно-системной рецепторной деятельности (ВЦСРД) [6].

Всеобщая целостно-системная рецепторная деятельность позволяет начать освоение целостно-системных рецепторных технологических средств деятельности (ЦСРТСД), которые выражают исполнительный рецепторный образ начального рецепторного целостно-системного субъекта. ЦСРТСД отражают те будущие характеристики рецепторного ряда, которые необходимо сформировать в процессе специально организованной целостно-системной рецепторной технологической деятельности (ЦСРТД). Данная деятельность выражает последовательность действий рецепторного системного анализа, который отражает поведение ЦСРТСД в определённых технологических условиях относительно ориентировочной, исполнительной и контрольной фазы [6].

ЦСРТД направлена на целостно-системный рецепторный предмет деятельности (ЦСРПРД), который отражает предметные условия рецепторного формирования ЦСРС. Этот рецепторный предмет обладает предварительными целостно-системными рецепторными характеристиками, которые необходимо сформировать в заданных условиях жизнедеятельности относительно внешних, целостных характеристик. При этом возникает целостно-системная рецепторная контрольная деятельность (ЦСРКД), которая направлена на установление соответствия между образом и будущим рецепторным прообразом цели жизнедеятельности на первой фазе самоформирования целостно-системного рецепторного супер-субъекта в форме рецепторного продукта деятельности.

Возникающий целостно-системный рецепторный продукт деятельности (ЦСРПРДД) устанавливает предметно-субъектные условия формирования нового типа рецепторного субъекта с минимаксными и максоминными параметрами. Процесс контрастного выражения параметров организуется в результате формирования целостно-системной рецепторной ритуальной деятельности (ЦСРРД), которая выполняет псевдо-ориентировочную основу самоформирования целостно-системного рецепторного супер-субъекта.

Результатом ЦСРРД является целостносистемная рецепторная опредмеченная потребность (ЦСРОП), которая выполняет роль псевдо-средств формирования целостносистемного рецепторного супер-субъекта (ЦСРСС). ЦСРОП через целостно-системную рецепторную восходящую деятельность (ЦСРВД) начинает формировать в процессе заданных рецепторных характеристик ориентировки, исполнения и контроля целостно-системный рецепторный компаунд-субъект (ЦСРКС). При этом ЦСРКС можно представить в виде целостно-системных рецепторных псевдосредств самоформирования ЦСРСС, который в окончательном виде возникает при организации целостно-системной рецепторной развивающей деятельности (ЦСРРЗД).

$$
\text { ЦСРРЗД формирует процесс }
$$
самовоспитания ЦСРСС по общим законам 
представления рецепторной развивающей ориентировки, исполнения и контроля. Целостносистемная рецепторная развивающая деятельность выполняет базисную контрольную рецепторную деятельность, когда возникают условия смыслообразования рецепторного образа супер-субъекта. Полное представление ЦСРСС организуется через рецепторный системный анализ, когда рецепторный образ представлен как система, отражённая в порождающем ряде целостно-системной рецепторной среды, выраженной через многоуровневый рецепторный образ в многочислен-ном ряде форм рецепторной организации, системных свойств, статического и динамического поведения мира рецепторности и представление перспектив развития целостносистемной рецепторики. Формирование футуралистической целостно-системной рецепторики должно отражать всеобщий базисный принцип эрцгамности полной структуры целостно-системного цикла жизнедеятельности в результате проявления педагого-метрического анализа рецепторных звёзд Эрцгаммы на фазах ориентировочного, исполнительного и контрольного рецепторного образа всеобщего развития смыслообразующего образа Мира относительно системной целостности [7].

Десятый этап формирования целостносистемного цикла жизнедеятельности связан с целостно-системной речистостью, которая выражает одну из следующих орудийных средств познания окружающего мира. Целостносистемная речистость - есть одна из высших форм взаимодействия с окружающим миром на основе целостно-системной ориентировочномотивационной деятельности материального восприятия действительности. Целостносистемная речистость выражает особую целостно-системную материальную жизнедеятельность, которая возникает и формируется на основе инвариантной структуры жизнедеятельности и определяет соответствующий уровень целостно-системной ориентировки, исполнения и контроля речевого восприятия [8].

Целостно-системная

речевая жизнедеятельность задаётся общим развитием целостно-системного субъекта и, в первую очередь, определяется соответствующими параметрами начального состояния целостносистемного материального субъекта, который характеризуется речевыми временными, гравитационными, силовыми, энергетическими, ориентировочными, исполнительными и контрольными параметрами.

Целостно-системный речевой субъект (ЦСРС) овладевает обобщённой целостносистемной речевой деятельностью (ЦСРД), которая формируется по базисным характеристикам деятельности, действия и операции в процессе их развития. Это позволяет приступить к освоению целостно-системных речевых средств деятельности (ЦСРСД), которые характеризуются определёнными параметрами, а также относительными сочетаниями их характеристик, которые отражают особенную целостно-системную технологию речевого восприятия мира относительной общей цели развития целостно-системного субъекта.

Возникающая технология целостносистемных речевых средств деятельности направлена на соответствующие целостносистемные речевые предметы деятельности (ЦСРПД), которые отражают определённые внешние параметры относительно силовых, гравитационных, энергетических, временных, пространственных, ориентационных, исполнительных и контрольных характеристик, их сочетаний и перестановок речевого предметного образа. При этом образуется целостно-системная речевая контрольная деятельность (ЦСРКД), которая в результате базисного структурного цикла ориентировки, исполнения и контроля устанавливает изоморфное соответствие между речевыми образами и прообразами речевой предметности [9].

Результатом целостно-системной речевой контрольной деятельности является целостносистемный речевой продукт деятельности (ЦСРПРД). который является многофункциональным субъектно-средственным предметом саморазвития целостно-системного речевой субъекта. Первой деятельной формой активации ЦСРПРД является целостно-системная речевая ритуальная деятельность (ЦСРРД), которая отражает особенные формы проявления активности ориентировочного, исполнительного и контрольного характера по установлению целостно-системной опредмеченной речевой потребности (ЦСОРП).

Целостно-системная опредмеченная речевая потребность является псевдосредством новой формы саморазвития целостно-системного речевого субъекта. ЦСОРП вызывает кардинальную форму целостно-системной речевой восходящей деятельности (ЦСРВД), которая формирует целостно-системный речевой компаунд-субъект (ЦСРКС). Он определяется как псевдо предмет самоформирования целостносистемного речевого супер-субъекта деятельности (ЦСРССД). Процесс перехода к высшей форме речевых субъектных отношений происходит через целостно-системную речевую развивающую деятельность (ЦСРРД), которая формирует ЦСРССД в результате выполнения базисных ориентировочных, исполнительных и 
контрольных материальных форм деятельности. Возникающий целостно-системный речевой супер-субъект деятельности отражает весь смыслообразующий компонент всего процесса целостно-системной речевой жизнедеятельности (ЦСРЖД).

Каждый элемент целостно-системной речевой жизнедеятельности имеет системное представление. На первом этапе системного анализа устанавливаются общие контуры системного представления с определением характеристик порождающей среды, внешних свойств элементов, уровней анализа, их структуры, формы организации, поведения и начальные прогнозы развития. В дальнейшем происходит раскрытие детализаций процесса целостно-системной материализации, как особой формы жизнедеятельности и этапа формирования абсолютной целостно-системной речевой суперличности, которая способна на данном этапе интериоризационного развития устанавливать пространственные, силовые, энергетические, временные, гравитационные, ориентировочные, исполнительные и контрольные параметры речевого восприятия, относительно структурных и системообразующих связей речевого образа внешнего мира, а также определять сложность, упорядоченность и разнообразие речевого ряда развития в условиях статического и динамического речевого ощущения относительно перспектив саморазвития субъекта. Формирование новых форм целостно-системной речистости должно отражать всеобщий базисный принцип эрцгамности полной структуры целостно-системного цикла жизнедеятельности в результате проявления педагогометрического анализа речевых звёзд Эрцгаммы на фазах ориентировочного, исполнительного и контрольного речевого образа всеобщего развития смыслообразующего образа Мира относительно системной целостности [10].

Выделенные последующие этапы формирования целостно-системной жизнедеятельности определяют условия адаптивного прогнозирования педагогометрической структуры этапов формирования целостно-системных циклов жизнедеятельности относительно образовательных объектов.

\section{References:}

1. Mishchik SA (2014) Pedagogometrika and mathematical modeling educational activity. Materialy Mezhdunarodnoy nauchnoy konferenctsii "Modern mathematics in science" - 30.06.2014. ISJ Theoretical \&Applied Science 6(14): 54-56 Caracas, Venezuela. doi: http://dx.doi.org/10.15863/TAS.2014.06.14.10

2. Mishchik SA (2014) Simulation training activity methods of mathematical logic. Materialy Mezhdunarodnoy nauchnoy konferenctsii "Eurapean Science and Education" - 30.07.2014. ISJ Theoretical \&Applied Science 6(15): 72-74 Marseille, France. doi: http://dx.doi.org/10.15863/TAS.2014.07.15.13

3. Mishchik SA (2014) Mathematical modeling system integrity-cycle of life activity - first goal pedagogometriki. Materialy Mezhdunarodnoy nauchnoy konferenctsii "European Applied Sciences" - 30.08.2014. ISJ Theoretical \&Applied Science 7(16): 77-79. Aix-en-Provence, France. doi: http://dx.doi.org/10.15863/TAS.2014.08.16.13

4. Mishchik SA (2014) Mathematical modeling system integrity-curricular activities - the second problem pedagogometriki. Materialy
Mezhdunarodnoy nauchnoy konferenctsii "European Innovation" - 30.09.2014. ISJ Theoretical \&Applied Science 9(17): 126-128 Martigues, $\quad$ France. doi: http://dx.doi.org/10.15863/TAS.2014.09.17.21

5. Mishchik SA (2014) Mathematical modeling holistic-systemic communicative activity - the third task pedagogometriki. Materialy Mezhdunarodnoy nauchnoy konferenctsii "European Scientific Achievements" 30.10.2014. ISJ Theoretical \&Applied Science 10(18): 45-47 Brighton, UK. doi: http://dx.doi.org/10.15863/TAS.2014.10.18.11

6. Mishchik SA (2014) Mathematical modeling integrity - system performance subject - fourth task pedagogometriki. Materialy Mezhdunarodnoy nauchnoy konferenctsii "Eurapean Science and Technology" 30.11.2014. ISJ Theoretical \&Applied Science 11(19): 51-54 Southampton, UK. doi: http://dx.doi.org/10.15863/TAS.2014.11.19.10

7. Mishchik SA (2015) Pedagogometrik - science and academic subject. Materialy Mezhdunarodnoy nauchnoy konferenctsii "European Technology in Science" 28.02.2015. ISJ Theoretical \& Applied Science 


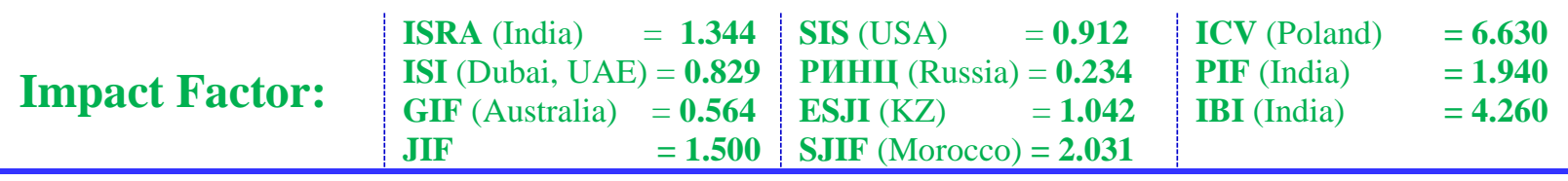

02 (22): 103-106 Malmö, Sweden. doi: http://dx.doi.org/10.15863/TAS.2015.02.22.17

8. Tokmazov GV (2014) Matematicheskoe modelirovanie $\mathrm{v}$ uchebno-professional'noy deyatel'nosti. Materialy Mezhdunarodnoy nauchnoy konferentsii «Modern mathematics in science» - 30.06.2014. ISJ Theoretical \& Applied Science 6(14): 44-46. - Caracas, Venezuela. doi: http://dx.doi.org/10.15863/TAS.2014.06.14.8

9. Tokmazov GV (2014) Analysis says study skills in the study of mathematics, Materialy Mezhdunarodnoy nauchnoy konferenctsii
"Eurapean Science and Education" 30.07.2014. ISJ Theoretical \&Applied Science 6(15): 72-74 Marseille, France. doi: http://dx.doi.org/10.15863/TAS.2014.06.14.

10. Tokmazov GV (2014) Mathematical modeling research skills in educational activity methods of probability theory. Materialy Mezhdunarodnoy nauchnoy konferenctsii "Eurapean Science and Technology" 30.11.2014. ISJ Theoretical \&Applied Science 11(20): 66-69 Southampton, United Kingdom. doi:

http://dx.doi.org/10.15863/TAS.2014.11.19.13 